\title{
Criterios para reparar a las víctimas del conflicto armado desde la perspectiva de la administración pública y del juez administrativo colombiano*
}

Criteria to Repair the Victims of the Armed Conflict from the Perspective of the Public Administration and the Colombian Administrative Judge

Margarita Cárdenas Poveda ${ }^{a}$

Universidad de la Sabana, Colombia

margarita.cardenas@unisabana.edu.co

ORCID: http://orcid.org/0000-0001-9922-6429
DOI: https://doi.org/10.11144/Javeriana.vj139.cprv

Recepción: 16 Enero 2018

Aceptación: 29 Agosto 2019

Fecha de publicación: 30 Diciembre 2019

\section{Resumen:}

Este artículo estudia, a través de un método descriptivo y explicativo, la manera como la Corte Constitucional y el Consejo de Estado colombianos, durante el periodo 2002-2017, ha establecido diversos criterios para reparar a las víctimas del conflicto armado por la vía administrativa y por la vía judicial a través de su jurisprudencia y teniendo en cuenta los regímenes legislativos de responsabilidad administrativa y el artículo 90 de la Constitución Política. Tanto en la reparación por vía administrativa como judicial, el legislador ha buscado reconocer integralmente los perjuicios ocasionados por la transgresión a los derechos humanos en el marco del conflicto armado y la jurisprudencia ha tenido un papel preponderante en el desarrollo de la misma. Sin embargo, la forma en la que se materializa la reparación, los beneficiarios y montos varían en función de la vía por la que se adelanten.

Palabras clave: Responsabilidad del Estado, reparación integral, reparación víctimas del conflicto armado, vía administrativa, vía judicial.

\section{Abstract:}

This article, through a descriptive and explanatory method, aims to describe the way of how the Colombian Constitutional Court and the Council of State have established diverse criteria to repair the victims of the armed conflict over the administrative and judicial track between the period of 2002-2017 through the jurisprudence and having in mind the legislative regimes of administrative responsibility and the 90th article of the Political Constitution,. In both administrative and judicial redress, the legislator has sought to give full recognition to the harm caused by human rights violations in the context of the armed conflict, and case law has played a leading role in the development of the conflict. However, how reparation is implemented, the beneficiaries and amounts vary depending on the route by which they are advanced.

Keywords: State responsibility, integral repair, armed conflict victims repair, administrative track, judicial track.

\section{Introducción}

En el Estado Social de Derecho, cuando se trata de la responsabilidad del Estado, lo relevante es la víctima ya que prima la tutela de la dignidad humana, el respeto de los derechos constitucionales, convencionales y de los derechos humanos. Es por eso que, ante el conflicto armado sufrido en Colombia durante décadas, el Estado, principalmente la Corte constitucional y el Consejo de Estado, se ha visto en la necesidad de promulgar diferentes estatutos legislativos de responsabilidad y a expedir jurisprudencia para la protección de los derechos de las víctimas con base al artículo 90 de la Carta Política, abarcando las decisiones de la Corte Interamericana de Derechos Humanos que ha marcado una línea inquebrantable, que concibe la reparación de las víctimas como un derecho fundamental.

Notas de autor

\footnotetext{
a Autor de correspondencia. Correo electrónico: margarita.cardenas@unisabana.edu.co
} 
Con la expedición de los diferentes regímenes legislativos de reparación administrativa se pretendió crear una política pública con mecanismos rápidos y masivos, de manera igualitaria y equitativa, para atender situaciones de violaciones graves y sistemáticas a los derechos humanos y lograr la materialización del derecho de reparación integral de las víctimas.

La jurisprudencia de la Corte Constitucional y del Consejo de Estado, al aplicar los criterios que emanan del sistema interamericano de derechos humanos, han determinado que la reparación integral de perjuicios tanto por vía administrativa como judicial no puede limitarse a una indemnización material. En efecto, se ha reconocido y protegido de manera categórica, pacifica, reiterada, clara y expresa, los derechos de las víctimas a la verdad, justicia y reparación integral materializados en una restitución, rehabilitación, satisfacción y garantía de no repetición por los menoscabos causados.

El problema que se planteó en este artículo consiste en determinar cuáles son los diferentes criterios de la reparación por vía administrativa y por vía judicial. Las fuentes utilizadas fueron documentales, principalmente correspondientes a la jurisprudencia del Consejo de Estado y de la Corte Constitucional durante el periodo comprendido entre 2002 a 2017, por encontrarse el mayor desarrollo jurisprudencial del objeto de esta investigación.

El método en la primera parte del artículo corresponde al descriptivo, porque se trató del origen de la reparación administrativa y las generalidades sobre el deber de reparar integralmente a las víctimas del conflicto armado colombiano. En la segunda parte es explicativo, ya que se estudian las providencias del Consejo de Estado y de la Corte Constitucional, para llegar a los resultados que se condensan en las conclusiones.

\section{El conflicto armado colombiano}

El Estado colombiano, ante la permanente violación de derechos a la población como consecuencia del conflicto interno armado, se ha visto en la obligación de establecer mecanismos concretos que le permitan reparar a las víctimas en el corto plazo.

Las reparaciones, si bien es cierto, no corresponden únicamente a indemnizaciones económicas, es necesario tener en cuenta la limitación de recursos con que cuenta el Estado para este fin, debido a que estos son insuficientes para cubrir las condenas decretadas por los jueces.

Los consensos a los que se ha llegado en Colombia para reparar a las víctimas del conflicto armado son tres: 1) El deber del Estado y el derecho de las víctimas de la Reparación Plena 2) Garantizar la reparación efectiva a través de vías judiciales y administrativas. 3) Crear una política pública destinada a la restitución de los bienes y tierras que han perdido las víctimas, por los actores armados ${ }^{[1]}$.

\section{El deber del Estado y el derecho de las víctimas de la reparación plena}

De acuerdo con la Ley de Justicia y Paz (975 de 2005) $)^{[2]}$, la responsabilidad por las violaciones a los derechos de las víctimas correspondía a quienes habían cometido los delitos. En ese orden de ideas, el daño antijurídico le era imputable al perpetrador, a quien debía exigirse la reparación, y en el caso que no se lograra identificar al sujeto activo, le correspondería el grupo al margen de la ley al cual pertenecía.

La Corte Constitucional ${ }^{[3]}$, mediante el control de constitucionalidad de la ley 975, determinó que la obligación de reparar correspondía, en primer lugar, a quienes habían llevado a cabo las conductas delictivas y de manera subsidiaria; con base en el principio de solidaridad, al grupo al que pertenecían los perpetradores y, finalmente, si sus recursos no eran suficientes para reparar a las víctimas, el Estado de manera residual debía hacerlo. 
La ley de víctimas y restitución de tierras ${ }^{[4]}$ definió las bases para la creación de una política pública de reparación integral a las víctimas del conflicto armado, correspondiéndole al Estado poner en marcha un programa administrativo de reparaciones. Es así como, de conformidad con los artículos 26 y 161 numeral 12 y 172 de la Ley 1448 de $2011^{[5]}$, en concordancia con el artículo 10 del decreto reglamentario 4800 de 2011, se dispone que las "entidades estatales tanto del nivel nacional como del territorial, tienen la responsabilidad de prevenir, asistir, atender y reparar integralmente a las víctimas en los términos de los artículos 3 y 9 de la Ley 1448 de 2011 conforme a sus competencias y responsabilidades"[6].

De acuerdo con la interpretación del enunciado jurídico transcrito, se establece con claridad que las víctimas no tendrán que acudir a los perpetradores de los daños para ser reparadas. Será el Estado, quien directamente y a través de un proceso administrativo deberá repararlas. Sin embargo, el texto de la ley establece de manera rotunda que las medidas de atención, asistencia y reparación, tendientes a reconocer los derechos de las víctimas a la verdad, justicia y reparación no conllevan reconocimiento por parte del Estado de una responsabilidad extracontractual derivada del daño antijurídico e imputable a éste, de conformidad en el artículo 90 de la Constitución Política. El reconocimiento por parte del Estado de la calidad de víctima ${ }^{[7]}$ no representa una prueba ante ninguna autoridad de la responsabilidad extracontractual del Estado o de sus agentes (Art. 9. Este precepto legal es reiterado por el Consejo de Estado ${ }^{[8]}$ al afirmar que el deber de reparar sigue correspondiendo a quien causa el daño, de tal manera que el Estado solo entra a cubrir los daños en forma residual para hacer efectivos los derechos de las víctimas, en especial, los de aquellas que no cuentan con una decisión judicial que fije el monto de la indemnización al que tienen derecho y ante la eventualidad de que los recursos de los perpetradores sean insuficientes.

\section{Garantía de reparación judicial y administrativa}

El acceso a la justicia en Colombia se encuentra consagrado en el artículo 229 de la Constitución Política. El derecho de acción es público y sus fundamentos se encuentran en los estatutos constitucionales de los diferentes países y en los tratados internacionales como, por ejemplo, en la Declaración Universal de los Derechos Humanos de las Naciones Unidas ${ }^{[9]}$. La acción es la facultad que tiene toda persona como un derecho público para acudir a los organismos jurisdiccionales con el fin de que se le reconozca un derecho subjetivo que considera tener.

No obstante, ser un derecho constitucional desde el punto de vista práctico presenta una serie de dificultades que impiden la materialización del acceso a la justicia, a lo anterior se suma el conflicto armado que ha vivido Colombia y que ha traído como consecuencia millones de víctimas, a quienes se les han violado toda clase de derechos y que deben ser reparadas de manera integral. Por lo expuesto, debieron desarrollarse mecanismos de reparación dentro del marco de la justicia transicional ${ }^{[10]}$, como es el de la reparación administrativa para que las víctimas tengan acceso, ya sea de manera individual o colectiva, a la administración de justicia sin que por ello se les cercene el derecho de accionar ante la jurisdicción ${ }^{[11]}$.

\section{Política pública para restitución de tierras}

Con la expedición de la Ley 1448 de 2011, se legisló sobre la restitución de tierras como un mecanismo mixto que incluye un procedimiento administrativo, referente a la inscripción en el registro de tierras despojadas y un procedimiento judicial, para la restitución material y jurídica de la tierra despojada ${ }^{[12]}$. Por ser un proceso atípico en el ordenamiento dado su carácter transicional, el legislador omitió que la restitución de tierras se surtiera por procedimientos ordinarios abreviados ${ }^{[13]}$. Son titulares del derecho a acudir a la restitución de 
tierras los propietarios, poseedores o explotadores de baldíos, que desde el 1 de enero de 1991 hayan sido despojados de sus tierras por ocasión del conflicto armado.

La Ley 1448 de $2011^{[14]}$ y el Decreto 4157 del mismo año establecieron que el Ministerio de Defensa Nacional y la fuerza pública, en coordinación con el Ministerio del Interior y de Justicia, el Ministerio de Agricultura y Desarrollo Rural, a través de la Unidad Administrativa Especial de Gestión de Restitución de Tierras Despojadas (URT), creada por esta Ley, contará con un Registro único de tierras despojadas y abandonadas para inscribir en los predios, y de las personas y familias despojadas para establecer la relación jurídica y material entre los que dicen ser desplazados y despojados y los bienes inmuebles ${ }^{[15]}$. Esta entidad tiene la función primordial de adoptar las medidas conducentes a la restitución jurídica y material de las tierras a los desplazados. Cuando no es posible materializar la restitución del bien, se debe reconocer una suma de dinero equivalente a su valor y, si se trata de bienes baldíos, se procede a la adjudicación del predio.

\section{La reparación integral - restitutio in integrum}

La reparación en el moderno estado social y democrático de derecho, tiene una doble naturaleza: como principio mediante el cual el sistema jurídico protege la esencia individualista de cada sujeto y como derecho para que, además de reparar la esfera personal de la víctima, esta reparación se realice dentro del nivel social al que pertenece, es decir, dejar indemne a la víctima dentro del contexto del estado social de derecho, teniendo en cuenta las particularidades que debe ofrecer el principio en el ámbito del conflicto armado o de perturbación permanente de derechos, libertades e intereses, como ocurre en Colombia desde hace décadas ${ }^{[16]}$.

La reparación no proviene únicamente de las acciones, omisiones o inactividad de las autoridades, sino también de la actividad desplegada por grupos ilegales, actores del conflicto armado que vulneran los derechos humanos y el derecho internacional humanitario ${ }^{[17]}$. De conformidad con los mandatos constitucionales y convencionales, se debe procurar la restitutio in integrum, que incluye no solo la indemnización económica ${ }^{[18]}$, sino la concreción del resarcimiento y el restablecimiento eficaz de los derechos, pues la reparación no puede ser únicamente de contenido económico, por el contrario, debe incorporar un contenido garantista.

En decisión de 2002 $2^{[19]}$, la Corte Constitucional hizo un estudio sobre el derecho de las víctimas y concluyó que la reparación con ocasión a un delito no puede limitarse a una reparación material. En efecto, señala que las autoridades tienen la obligación de utilizar todos los instrumentos judiciales para llegar al goce efectivo verdad, justicia y reparación- del resarcimiento integral.

A su vez, la Corte Constitucional indica que, a la luz del derecho internacional, resulta insuficiente para la protección efectiva de los derechos humanos limitarse a una compensación, toda vez que la verdad y la justicia son elementos perentorios que se deben valorar al momento de indemnizar cualquier perjuicio, y más, cuando se ocasiona con la transgresión a los derechos humanos. Posteriormente, la Corte ${ }^{[20]}$ efectúa una valoración al derecho de reparación en virtud del derecho internacional contemporáneo y concluye que el mismo abarca dos dimensiones: una individual y otra colectiva. Frente a la dimensión individual señala que comprende todos los perjuicios sufridos por la víctima y que, para su resarcimiento, se requiere medidas de restitución, indemnización, rehabilitación, satisfacción y garantía de no repetición. La dimensión colectiva involucra medidas de satisfacción para restaurar, indemnizar o readaptar los derechos de las colectividades o comunidades $^{[21]}$.

En sentencia C-099/2013 ${ }^{[22]}$ se pronuncia sobre la restitución de tierras y establece que el proceso para este fin se ha establecido como un parámetro inquebrantable, buscando resarcir integralmente: i) el reconocimiento expreso del derecho a la reparación del daño causado que le asiste a las personas que han sido objeto de violaciones de derechos humanos; ii) el derecho a la reparación integral y las 
medidas que este derecho incluyese regulados por el derecho internacional en todos los aspectos; iii) el derecho a la reparación de las víctimas es integral, en la medida que se deben adoptar distintas medidas determinadas no solo por la justicia distributiva sino también por la justicia restaurativa; iv) las obligaciones de reparación incluyen de manera preferente la restitución plena; v) de no ser posible tal resarcimiento pleno es procedente la compensación a través de medidas como la indemnización pecuniaria; vi) la reparación integral además de la restitución y compensación incluye medidas tales como la rehabilitación, satisfacción y no repetición; vii) la reparación integral a las víctimas de graves violaciones a los derechos humanos tiene una dimensión individual como colectiva; viii) en su dimensión individual comprende medidas de restitución, indemnización, readaptación o rehabilitación; ix) en su dimensión colectiva la reparación se obtiene a través de medidas de satisfacción de carácter simbólico; $\mathrm{x}$ ) una medida importante de reparación integral es el reconocimiento público del crimen cometido y el reproche de tal actuación; xi) el derecho a la reparación desborda el campo de la reparación economía, e incluye además medidas como el derecho a la verdad y a que se haga justicia; y, xii) la reparación integral a las víctimas debe diferenciarse de la asistencia y servicios sociales y de la ayuda humanitaria brindada por el Estado, de manera que no pueden confundirse entre sí, lo que, a su vez, reitera en jurisprudencia de $2017^{[23]}$, al afirmar que el Estado debe garantizar la protección y ejercicio de medidas que permitan a las víctimas conocer la verdad de lo ocurrido con ocasión a la transgresión de derechos humanos; destacando así, que la reparación integral es una obligación del Estado cuya finalidad es devolver a la víctima al estado en el que se encontraba con anterioridad al hecho que originó tal condición.

"La reparación responde a una serie de modalidades, reconocidas en el derecho interno, en el derecho convencional y en derecho internacional público ${ }^{[24]}$ : a) la restitución; b) la indemnización; c) la rehabilitación; d) la garantía de no repetición, y f) las medidas de satisfacción" ${ }^{25]}$.

En la reparación administrativa, como lo ordena la Ley de Víctimas y Restitución de Tierras ${ }^{[26]}$ debe darse el restablecimiento integral del perjuicio.

El Consejo de Estado se ha pronunciado al respecto y coincide en afirmar que la reparación ya sea por vía judicial o administrativa debe propender por la restitutio in integrum.

“... Debe colegirse, por lo tanto, que el principio de reparación integral, entendido como el precepto que orienta el resarcimiento de un daño, con el fin de que la persona que lo padezca sea llevada, al menos, a un punto cercano al que se encontraba antes de la ocurrencia del mismo, debe ser interpretado y aplicado de conformidad al tipo de daño producido, es decir, bien que se trate de uno derivado a la violación de un derecho humano, según el reconocimiento positivo del orden nacional e internacional, o que se refiera a la lesión de un bien o interés jurídico que no se relaciona con el Sistema de Derechos Humanos (DDHH).

En esa perspectiva, la reparación integral en el ámbito de los derechos humanos supone, no solo el resarcimiento de los daños y perjuicios que se derivan, naturalmente, de una violación a las garantías de las personas reconocidas internacionalmente, sino que también implica la búsqueda del restablecimiento del derecho vulnerado, motivo por el cual se adoptan una serie de medidas simbólicas y conmemorativas, que no propenden por la reparación de un daño (strictu sensu), sino por la restitución del núcleo esencial del derecho o derechos infringidos. Por el contrario, la reparación integral que opera en relación con los daños derivados de la lesión a un bien jurídicamente tutelado, diferente a un derecho humano, se relaciona, específicamente, con la posibilidad de indemnizar plenamente todos los perjuicios que la conducta vulnerante ha generado, sean éstos del orden material o inmaterial. Entonces, si bien el juez no adopta medidas simbólicas, conmemorativas, de rehabilitación, o de no repetición, dicha circunstancia, per se, no supone que no se repare íntegramente el perjuicio" [27].

La protección de los derechos fundamentales fijados en concordancia con lo establecido por la Convención Interamericana de Derechos Humanos, en particular la desaparición forzada, afecta múltiples bienes jurídicos tales como la vida, integridad personal, libertad y dignidad.

Respecto de la reparación de delitos de lesa humanidad, el Consejo de Estado indica que la indemnización debe incluir los principios de justicia, verdad y reparación integral, pues han sido catalogados por la jurisprudencia interamericana como derechos fundamentales que se rigen en virtud del ius cogens ${ }^{[28]}$. 
Como lo expresan Uprimny y Saffon, teniendo en cuenta la jurisprudencia de la Corte Interamericana de Derechos Humanos que ordena en sus sentencias ${ }^{[29]}$ la reparación, esta incluye la restitución y la rehabilitación dependiendo del caso, y la indemnización o compensación, la satisfacción y las garantías de no repetición en la mayoría de las veces.

Existe coincidencia entre lo expuesto por el Consejo de Estado y la doctrina como se corrobora a continuación:

\begin{abstract}
"En primer lugar, la restitución busca devolver a la víctima a la situación anterior a la violación de su derecho, cuando es procedente y a la víctima le interesa, mediante la devolución de sus bienes patrimoniales y con el restablecimiento de sus derechos y de su situación personal, familiar, laboral y social. En segundo lugar, a través de la compensación o indemnización se busca reparar a las víctimas por los daños materiales físicos, mentales, a la reputación y a la dignidad sufridos, los gastos incurridos, las pérdidas de ingreso y de oportunidades, y los costos de asistencia jurídica y servicios médicos, entre otros, cuando no sea posible la restitución a la situación anterior o cuando las víctimas no la deseen. En tercer lugar, los mecanismos de rehabilitación incluyen la atención médica y psicológica y los servicios jurídicos y sociales que requieran las víctimas. En cuarto lugar, las medidas de satisfacción buscan reconocer públicamente el daño sufrido por las víctimas y a través de ello identificarlas, para lo cual incluye, entre otras, la investigación y sanción de los responsables de los crímenes, la difusión de la verdad, la búsqueda de los desaparecidos y de los restos de los muertos, la solicitud pública de disculpas y la realización de conmemoraciones y homenajes a las víctimas. Y, en quinto lugar, las garantías de no repetición consisten en reformas institucionales y en medidas de otra naturaleza que buscan evitar que las atrocidades vuelvan a cometerse, y con las cuales se promueve el Estado de derecho y el respeto de los derechos humanos y de los procesos democráticos, se derogan leyes que contribuyen o autorizan las violaciones, se garantiza el control de las fuerzas armadas, de seguridad y de inteligencia, se procura el desmantelamiento de las fuerzas armadas paraestatales y la reintegración social de niños combatientes, entre otros beneficios" ${ }^{\mathrm{n}}[30]$.
\end{abstract}

Finalmente, la Ley 1448 de 2011 en su artículo 25, tiene la misma conceptualización de lo que es y conforma la reparación integral.

\title{
Criterios de la reparación administrativa y la reparación judicial
}

Una vez expuesto en qué consiste la reparación integral en la sección anterior, en esta, se establecen los principales criterios existentes para reparar por la vía administrativa y la judicial, de conformidad con la jurisprudencia más importante de la Corte Constitucional y del Consejo de Estado.

A La Unidad Administrativa Especial para la Atención y Reparación Integral de las Victimas, adscrita al Departamento de la Prosperidad Social (DPS), le corresponde la operación de la Red Nacional de Información del Registro Único de Víctimas (RUV) y participa con otras instituciones del Estado en el Sistema Nacional de Atención y Reparación Integral a las víctimas (SNARIV).

De acuerdo con la información suministrada por la Unidad para la Atención y Reparación Integral a las Víctimas (UARIV), en el Registro Único de Víctimas (RUV), hasta el año 2017, se encuentran registradas 8.604.210, de estas 8.270.812, son víctimas del conflicto armado ${ }^{[31]}$.

El artículo $90^{[32]}$ de la Constitución Política es garantía de la responsabilidad patrimonial extracontractual del Estado por los daños antijurídicos que le sean imputables, que se causen por la acción u omisión de las autoridades. Tradicionalmente, a través del poder judicial (civil, penal, administrativo, Justicia y Paz) se tiene acceso a la satisfacción de los derechos subjetivos e intereses legítimos, es decir, la reparación por los daños causados a las personas, pero la administración de justicia también es prestada por las entidades administrativas ${ }^{[33]}$, cuya fuente por lo general corresponde a los Regímenes Legislativos de Responsabilidad que son subsidiarios, implican el pago de una compensación previamente establecida en una ley, para determinadas situaciones ${ }^{[34]}$ cuando se causa un daño, como ocurre con la Ley de Víctimas y Restitución de Tierras en Colombia. Las víctimas también están facultadas para acudir ante jurisdicciones internacionales, como la Corte Interamericana de Derechos Humanos o la Corte Penal Internacional ${ }^{[35]}$. 


\section{Jurisprudencia de la Corte Constitucional y del Consejo de Estado}

La Corte Constitucional en la sentencia T $370 / 2013^{[36]}$ señala que la reparación administrativa se caracteriza por ser un mecanismo de carácter masivo, que ofrece una vía expedita que facilita el acceso de las víctimas a la reparación; mientras que la reparación en sede judicial hace énfasis en el otorgamiento de justicia a personas individualmente consideradas, examinando caso por caso las violaciones.

La Corte Constitucional hace un análisis sobre los cuerpos normativos que permiten a las víctimas del conflicto armado obtener la reparación integral; en este sentido, entre las medidas de reparación se encuentra la indemnización administrativa, cuyos criterios de distribución y montos, así como el procedimiento, están fijados expresamente por la ley y sus reglamentos ${ }^{[37]}$.

De igual forma, el Tribunal Constitucional ${ }^{[38]}$ que conforme al artículo 2 de la Constitución ha determinado que el propósito de la reparación por vía administrativa es atender situaciones de manera igualitaria y equitativa los casos de violaciones graves, masivas, y sistemáticas a los derechos humanos. A su vez, argumenta que la reparación en sede administrativa es propia de los contextos de justicia transicional y se adelanta a través de programas de carácter masivo, con los cuales se busca reparar a una gran cantidad de víctimas, atendiendo a criterios de equidad. De pretenderse una reparación integral, en cuanto comprende diferentes componentes o medidas de reparación, no es probable lograr una reparación plena del daño para cada víctima, ya que, a diferencia de la vía judicial, es difícil determinar con exactitud la dimensión, proporción o cuantía del daño sufrido.

En 2014 ${ }^{[39]}$, el Consejo de Estado hizo referencia al Programa de Reparación individual por vía administrativa para las víctimas de los grupos armados al margen de la ley, que incorporó como medidas de reparación: la restitución, la rehabilitación, medidas de satisfacción, garantías de no repetición e indemnización solidaria ${ }^{[40]}$. En complemento con las medidas de reparación ${ }^{[41]}$, la corporación analizó la ley 1448 de 2011 en lo concerniente a medidas de atención, asistencia y reparación integral en cabeza del Estado, así como la procura de garantías y condiciones para que la sociedad avance en la reconstrucción de la memoria histórica y establezca el derecho a la verdad que corresponde tanto a las víctimas como a la sociedad.

En concreto, las reparaciones judiciales se pueden pretender a través de la jurisdicción penal o contenciosa administrativa, mientras que las reparaciones administrativas están a cargo de autoridades administrativas. En el caso colombiano corresponde a la Unidad Administrativa para la Atención y Reparación Integral a las Víctimas y un Sistema de Atención y Reparación a las Víctimas de acuerdo con la Ley 1448 de 2011.

De un lado, en la reparación en sede judicial la responsabilidad se configura conforme al artículo 90 de la Constitución Política y los efectos son únicamente para las víctimas, es decir, personas individualmente consideradas que acuden a la jurisdicción contenciosa. En ésta, se articula la investigación y sanción de los responsables, y es el juez a quien le corresponde identificar los daños y montos a pagar por los perjuicios materiales o inmateriales causados a la víctima por la acción, inactividad u omisión del Estado.

Por otro lado, en los procesos de reparación por vía administrativa, el fundamento de la responsabilidad se encuentra en el artículo 2 de la Constitución Política, el cual consagra la posición de garante del Estado ${ }^{\text {[42] }}$ frente a sus administrados en relación con sus derechos fundamentales. Estos procesos plantean mecanismos masivos para atender situaciones de violaciones graves y sistemáticas a los derechos humanos de manera igualitaria y equitativa, a través de instancias rápidas, económicas y más flexibles en materia probatoria, lo que imposibilita la reparación plena del perjuicio sufrido. La reparación conlleva la restitución, compensación, indemnización, rehabilitación y medidas de no repetición.

En todo caso, la reparación judicial incorpora estos mismos mecanismos, pero el juez otorga únicamente lo solicitado por las víctimas, sin perjuicio de fallos ultra patita por parte del Consejo de Estado ${ }^{[43]}$, sobre todo cuando se trata de reparación material. 
Ahora bien, la reparación por vía administrativa no se lleva a cabo con base en el principio de solidaridad que es el fundamento para la ayuda humanitaria y atención o servicio social por parte del Estado, sino en el principio de responsabilidad del Estado, como garante de los derechos fundamentales en materia de responsabilidad frente a la reparación por vía administrativa. De modo que, mientras que las reparaciones administrativas no pretenden la restitución plena de los daños causados a las víctimas, las judiciales sí otorgan este tipo de reparación.

Por otra parte, en las reparaciones administrativas, en tanto debe tratarse de una vía fácil, rápida y efectiva para las víctimas, hay una flexibilización de la prueba, de manera que solo se exige una prueba sumaria tanto de la condición de víctima como del daño sufrido. Por el contrario, en la reparación judicial debe probarse plenamente la responsabilidad del Estado, sin importar el tiempo requerido y las dificultades que se presenten para su aportación al proceso ${ }^{[44]}$.

Para acceder a la reparación por vía administrativa las víctimas deben estar inscritas en el Registro Único de Victimas y presentar petición ante la Unidad Administrativa Especial para la Atención y Reparación Integral a las Víctimas con una condición restrictiva respecto de la fecha de la ocurrencia de los hechos. Las personas que hayan sufrido un daño posterior al 1 de enero de 1985 serán consideradas víctimas, sin embargo, sus hechos deben ser denunciados dentro de los siguientes dos o cuatro años contados a partir de la publicación de la Ley. En la reparación judicial el término será el correspondiente al medio de control para demandar por responsabilidad extracontractual del Estado.

Respecto a la relación entre la reparación por vía administrativa y la reparación por vía judicial, el Consejo de Estado ${ }^{[45]}$, en el año 2012, indicó que la creación de instrumentos como la reparación por vía administrativa, si bien son producto de la búsqueda del Estado de procurar el goce efectivo de los derechos a la verdad, justicia y reparación de las víctimas, no agotan el deber del Estado de garantizar que las víctimas ejerzan su derecho al acceso de justicia. Por lo tanto, los programas de reparación administrativa deben ser complementarios a la actividad judicial en la búsqueda de la reparación integral del daño y su tasación, así como del esclarecimiento de la verdad.

Finalmente, en relación con la indemnización administrativa, en dos casos relacionados con la destrucción de bienes inmuebles en enfrentamientos entre un grupo armado y agentes del Estado, el Consejo de Estado estableció dos criterios, el primero consistente en que es necesario verificar si la persona ha recibido valor alguno de los subsidios que otorga la ley 1448 de $2011^{[46]}$ para determinar el valor total al que puede acceder una víctima de conflicto armado a través de una acción judicial, y, el segundo, si la víctima recibió algún subsidio, dicho valor deberá ser descontado de la reparación final, de lo contrario se constituirá un enriquecimiento $\sin$ justa causa ${ }^{[47]}$.

Lo anterior, es acorde con lo establecido en el artículo 20 de la ley 1448 de 2011, que indica el principio de prohibición de doble reparación y compensación.

En el texto Contenido y alcance del derecho a la reparación publicado por la Defensoría del Pueblo de Colombia y la GIZ -Deutsche Gesellschaft fur Internationale Zusammenarbeit-, frente a las diferencias entre reparación administrativa y reparación judicial consideran que en las reparaciones por vía judicial la asignación de las medidas reparatorias a las víctimas corresponde a la decisión de una autoridad judicial competente y preestablecida, en aplicación de la legislación nacional, la jurisprudencia y el derecho internacional de los derechos humanos e implica altos costos económicos, de tiempo y emocionales, debido a que son las víctimas las que están en la obligación de probar quienes son sus victimarios y los daños denunciados en la demanda ${ }^{[48]}$.

En el derecho internacional de los derechos humanos ${ }^{[49]}$ no existe, expresamente una obligación jurídica internacional vinculante que estipule la obligación de crear programas de reparación administrativa con alcance masivo, estos se derivan del deber de 
“asegurar recuperaciones eficaces, cualificadas por características de equidad, adecuación, accesibilidad, efectividad, prontitud y facilidad, y con el objeto de utilizar de manera óptima los recursos a su disposición, los Estados están facultados para hacer uso de mecanismos no judiciales de reparación de víctimas"[50].

\section{Conclusiones}

Tanto en la reparación por vía administrativa como judicial, el legislador ha buscado reconocer integralmente los perjuicios a las víctimas ocasionados por la transgresión a los derechos humanos en el conflicto armado. La jurisprudencia, como fuente de derecho partiendo de casos particulares, ha jugado un papel preponderante en el desarrollo de la reparación de daños producto de conductas cometidas por grupos al margen de la ley.

Sin embargo, existen diferentes criterios en cada una de las dos vías, como se expuso a lo largo de este escrito y que son:

El fundamento constitucional de la reparación administrativa se basa en el artículo 2 superior y en la reparación judicial es el artículo 90 de la Carta Política. La reparación administrativa es de carácter masivo, en la mayoría de los casos, mientras que la judicial corresponde a personas individualmente consideradas.

La aplicación de la reparación administrativa como instrumento resarcitorio pretende, en teoría, plantear una novedosa formula de indemnización integral; no obstante, en la práctica su misma normatividad transgrede este principio, toda vez que la víctima está sometida a los montos que por ley se determinan para el resarcimiento del daño. En relación con las condenas económicas al Estado a través de la reparación por vía administrativa, son de carácter subsidiario y no se podrá imputar al Estado responsabilidad extracontractual por los daños causados a las víctimas, en los términos del artículo 90 de la Constitución Política.

En cuanto a los beneficiarios, en la reparación administrativa se verá favorecido el núcleo familiar que reclama, mientras que en la reparación judicial serán beneficiados aquellos que el juez reconozca como víctimas en el fallo, aclarando que en la primera usualmente no hay una reparación plena del daño en la medida que no se puede establecer con exactitud su cuantía, como consecuencia de la facilidad que tienen las víctimas para acceder a la reparación. Esta accesibilidad ocurre debido a que se trata de procesos rápidos, económicos y flexibles, que exigen prueba sumaria tanto de la condición de víctima como del daño sufrido. Por el contrario, en la vía judicial existe mayor probabilidad de que la reparación sea integral pero el proceso demanda extensos periodos de tiempo, altos costos económicos y psicológicos a la víctima, además debe probar plenamente quien fue el perpetrador y el daño causado.

Finalmente, en cuanto a los montos a indemnizar en la reparación administrativa, estos se encuentran establecidos en el decreto 4800 del 2011, mientras que en la reparación judicial corresponde a los establecidos en los baremos, construidos por el Consejo de Estado de acuerdo con el tipo de daño causado tanto a las víctimas directas como indirectas.

\section{Bibliografía}

Andrés Casas-Casas y Germán Herrera-Toloza, El juego politico de las reparaciones: un marco analítico de las reparaciones en procesos de justicia transicional, 13 Papel Político. n. ${ }^{\circ}$ 1, 197 -223 (2018). http://www.scielo.org.co/pdf/pap el/v13n1/v13n1a07.pdf

Aura Patricia Bolívar Jaime, Mecanismos de reparación en perspectiva comparada, en Reparar en Colombia: los dilemas en contextos de conflicto, pobreza y exclusión 74 (Catalina Díaz Gómez, Nelson Camilo Sánchez, Rodrigo Uprimny Yepes eds., 2009).

Catalina Díaz Gómez, Nelson Camilo Sánchez, Rodrigo Uprimny Yepes, Reparar en Colombia los dilemas en contextos de conflicto, pobreza y exclusión., Ed. Centro Internacional para la Justicia Transicional (ICTJ) y Centro de Estudios de Derecho, Justicia y Sociedad (Dejusticia), (1 ${ }^{\text {ra }}$ ed., 2009). https://www.ictj.org/sites/def ault/files/ICTJ-Colombia-Dilemas-Contextos-Conflicto-2009-Spanish.pdf 
Christine Bréchon-Moulénes, Les Régimes Législatifs de Responsabilité Publique, 112 Bibliothèque de droit public, 9, 559 (1974).

Consejo de Estado. Radicación n. ${ }^{\circ}$ 19001-23-31-000-1999-01166-01. Sentencia 22732. Consejero Ponente: Mauricio Fajardo Gómez; 20 de mayo de 2013.

Consejo de Estado. Sala de lo Contencioso Administrativo, Sección Tercera, Radicación n. ${ }^{\circ}$ 76001-23-25-000-1996-04058-01(16996). Sentencia del 20 de febrero 2008. Consejero Ponente: Enrique Gil Botero.

Consejo De Estado. Sala de lo Contencioso Administrativo, Sección Tercera. Radicación n. ${ }^{\circ}$ 07001-23-31-000-2000-00182-01. Sentencia del 18 De julio de 2012. Consejero Ponente: Olga Mélida Valle De La Hoz.

Consejo de Estado. Sala de lo Contencioso Administrativo, Sección Tercera. Radicación n. ${ }^{\circ}$ 25000-23-26-000-1996-02964(19807). Sentencia del 16 de marzo de 2012. Consejero Ponente: Stella Conto Díaz Del Castillo.

Consejo de Estado. Sala de lo Contencioso Administrativo, Sección Tercera. Radicación n. ${ }^{\circ}$ 19001-23-31-000-1999-00984-01. Sentencia 24108 del 1 de Julio de 2015. Consejera Ponente: Olga Mélida Valle De La Hoz.

Consejo de Estado. Sección 2, Subsección B. Sentencia de 10 de noviembre de 2014. Consejero Ponente: Gerardo Arenas Monsalve.

Consejo de Estado. Sección Primera. Radicación n. ${ }^{\circ} 11001-03-24-000-2009-00129-00$. Sentencia de 16 de abril de 2015. Consejero Ponente: Marco Antonio Velilla Moreno.

Consejo de Estado. Sección Tercera, Subsección B. Sentencia 19939 del 27 de septiembre de 2013. Consejero Ponente: Stella Conto Díaz del Castillo.

Consejo de Estado. Sección Tercera, Subsección C. Sentencia 28417 de 22 de enero de 2014, Consejero Ponente: Enrique Gil Botero.

Consejo de Estado. Sección Tercera, Subsección C. Sentencia 30385 del 1 de julio de 2015. Consejero Ponente: Jaime Orlando Santofimio Gamboa.

Constitución Política de Colombia [Const]. Art. 25.7 de julio de 1991 (Colombia).

Constitución Política de Colombia [Const]. Art. 90.7 de julio de 1991 (Colombia).

Corte Constitucional de Colombia, s Sentencia C 006/ 2017 del dieciocho (18) de enero de dos mil diecisiete (2017). Magistrado Ponente: María Victoria Calle Correa.

Corte Constitucional de Colombia, s. Sentencia T 370/ 2013 del veintisiete (27) de junio de dos mil trece (2013). Magistrado Ponente: Jorge Iván Palacio Palacio.

Corte Constitucional de Colombia, s. Sentencia T 908 / 2014 del 26 de noviembre de dos mil catorce (2014). Magistrado Ponente: Mauricio González Cuervo.

Corte Constitucional de Colombia, Sentencia C-916 del 29 de octubre de 2002. Magistrado Ponente: Manuel José Cepeda Espinosa.

Corte Constitucional de Colombia. Sentencia C-286 del 20 de mayo de 2014. Magistrado Ponente: Luis Ernesto Vargas Silva.

Corte Constitucional de Colombia. Sentencia C-099 del 27 de febrero de 2013. Magistrado Ponente: María Victoria Calle Correa.

Corte Constitucional de Colombia. Sentencia C 228 del 3 de abril de 2002. Magistrado Ponente: Manuel José Cepeda Espinosa y Eduardo Montealegre Lynett.

Corte Constitucional de Colombia. Sentencia C 370/06 del 18 de mayo de 2006. Magistrado Ponente: Manuel José Cepeda Espinosa y otros.

Corte Constitucional de Colombia. Sentencia C 454/2006 del 7 de junio de 2006. Magistrado Ponente: Jaime Córdoba Triviño corregida por el Auto 248 de 2006. 
Corte Constitucional de Colombia. Sentencia C-370 del 18 de mayo de 2006. Magistrado Ponente: Manuel José Cepeda Espinosa.

Corte Constitucional de Colombia. Sentencia C-529 del 23 de junio de 2010. Magistrado Ponente: Mauricio González Cuervo.

Corte Constitucional de Colombia. Sentencia C-771 del 13 de octubre de 2011. Magistrado Ponente: Nilson Pinilla Pinilla.

Corte Constitucional de Colombia. Sentencia SU-254 del veinticuatro (24) de abril de dos mil trece (2013). Magistrado Ponente: Luis Ernesto Vargas Silva.

Corte Constitucional de Colombia. Sentencia T 458 del 15 de junio de 2010. Magistrado Ponente: Luis Ernesto Vargas Silva.

Corte Constitucional, s de Colombia. Sentencia T 083 / 2017 del trece (13) de febrero de dos mil diecisiete (2017),. Magistrado Ponente: Alejandro Linares Cantillo.

Corte Interamericana de Derechos Humanos. Sentencia de 5 de julio de 2004, serie C, No. 109. Caso de la masacre de 19 comerciantes vs. Colombia,.

Corte Interamericana de Derechos Humanos. Sentencia de 1 de julio de 2006, serie C, No. 149.Caso de las masacres de Ituango vs. Colombia.

Corte Interamericana de Derechos Humanos. Sentencia de 11 de mayo de 2007, serie C, No. 163. Caso de la masacre de La Rochela vs. Colombia

Corte Interamericana de Derechos Humanos. Sentencia de 15 de septiembre de 2005, serie C, No. 134. Caso de la masacre de Mapiripa\#n vs. Colombia.

Corte Interamericana de Derechos Humanos. Sentencia de 31 de enero de 2006, serie C, No. 140.Caso de la masacre de Pueblo Bello vs. Colombia.

Corte interamericana de derechos humanos. Sentencia del 31 de enero de 2006. Caso la masacre de Pueblo Viejo vs Colombia.

Decreto 4800 de 2011 [Presidencia de la República de Colombia]. Por medio de la cual se reglamenta la Ley 1448 de 2011 y se dictan otras disposiciones. D.O. n. ${ }^{\circ} 48280.20$ de diciembre de 2011.

Defensoría del Pueblo y GIZ (Deutsche Gesellschaft fur Internationale Zusammenarbeit), Contenido y Alcance del Derecho a la Reparación. Instrumentos para la protección y observancia de las víctimas. http://www.defensori a.gov.co/public/pdf/04/alcanceReparacion.pdf

Instituto de Ciencia Política Hernán Echavarría Olózaga, Análisis de la Ley de Victimas y Restitución de Tierras - Ley 1448 de 2011: Antecedentes, logros y desafios desde la óptica del Desarrollo Rural, Nota de política Rural, n. ${ }^{\circ}$, 1-8 (2014).

Jaime Orlando Santofimio Gamboa, Compendio de derecho administrativo, Ed. Universidad Externado de Colombia, 779-782 ( $1^{\text {ra }}$ ed., 2017).

Ley 975 de 25 de julio de 2005. Por medio de la cual se dictan disposiciones para la reincorporación de miembros de grupos armados organizados al margen de la ley, que contribuyan de manera efectiva a la consecución de la paz nacional y se dictan otras disposiciones para acuerdos humanitarios. D.O. n. ${ }^{\circ} 45.980$.

Ley 1448 de 2011. Por la cual se dictan medidas de atención, asistencia y reparación integral a las víctimas del conflicto armado interno y se dictan otras disposiciones. 10 de junio de 2011. D.O. n. 48096.

Miguel Emilio La Rota, Sebastián Lalinde Ordoñez, Sandra Santa Mora y Rodrigo Uprimny Yepes. Necesidades Juri\#dicas y acceso a la Justicia en Colombia, Ed. Dejusticia, 215 (2014). https://www.dejusticia.org/wp-conte nt/uploads/2017/04/fi_name_recurso_665.pdf

Nelson Camilo León y Rodrigo Uprimny. La restitución de tierras, los imperativos de la justicia transicional y los principios del derecho privado, en Democracia, Justicia y Sociedad. Diez años de investigación en Dejusticia, 723 (Mauricio García Villegas, María Adelaida Ceballos Bedolla eds., 2016).

Organización de las Naciones Unidas. Declaración Universal de los Derechos Humanos, art. 10, (1948). https://ww w.ohchr.org/EN/UDHR/Documents/UDHR_Translations/spn.pdf 
Registro único de víctimas. https://www.unidadvictimas.gov.co/es/registro-unico-de-victimas-ruv/37394

Rodrigo Uprimny y María Paula Saffon, Reparaciones transformadoras, justicia distributiva y profundización democrática, en Reparar en Colombia: los dilemas en contextos de conflicto, pobreza y exclusión 40-41 (Catalina Díaz Gómez, Nelson Camilo Sánchez, Rodrigo Uprimny Yepes eds., 2009).

\section{Notas}

* Artículo de investigación. Este artículo es producto del proyecto de investigación: "Hacia la unificación del concepto de la responsabilidad civil y del Estado", Grupo de Investigación “Justicia, ámbito público y Derechos Humanos”, clasificado en Categoría A, 2017.

[1] Catalina Díaz Gómez, Nelson Camilo Sánchez, Rodrigo Uprimny Yepes, Reparar en Colombia: Los dilemas en contexto de conflicto, de pobreza y exclusión, 18 ( $1^{\text {ra }}$ ed., 2009).

[2] Ley 975 de 25 de julio de 2005. Por medio de la cual se dictan disposiciones para la reincorporación de miembros de grupos armados organizados al margen de la ley, que contribuyan de manera efectiva a la consecución de la paz nacional y se dictan otras disposiciones para acuerdos humanitarios. D.O. n. ${ }^{\circ} 45.980$.

[3] Corte Constitucional de Colombia. Sentencia C-370 del 18 de mayo de 2006. Magistrado Ponente: Manuel José Cepeda Espinosa.

[4] Ley 1448 de 2011. Por la cual se dictan medidas de atención, asistencia y reparación integral a las víctimas del conflicto armado interno y se dictan otras disposiciones. 10 de junio de 2011. D.O. n. ${ }^{\circ} 48096$., art 9

[5] Id. Art 3, 9, 26, 161 numeral 12 y 172.

[6] Decreto 4800 de 2011 [Presidencia de la República de Colombia]. Por medio de la cual se reglamenta la Ley 1448 de 2011 y se dictan otras disposiciones. D.O. n. ${ }^{\circ} 48280.20$ de diciembre de 2011. Art. 10.

[7] Ver Consejo de Estado. Sección Tercera, Subsección C. Sentencia 30385 del 1 de julio de 2015. Consejero Ponente: Jaime Orlando Santofimio Gamboa. "la víctima es todo sujeto, individuo o persona que sufre un menoscabo, violación o vulneración en el goce o disfrute de los derechos humanos consagrados en las normas convencionales y constitucionales, o que se afecta en sus garantías del derecho internacional humanitario. En este sentido, adaptando la definición atrás referida al caso en concreto, reconoce como hechos que erigen la condición de víctima: i) el desplazamiento intraurbano; ii) el confinamiento de la población; iii) la violencia sexual contra las mujeres; iv) la violencia generalizada; v) las amenazas provenientes de actores desmovilizados; vi) las acciones ilegitimas del Estado; vii) las acciones atípicas del Estado; viii) los hechos atribuibles a bandas criminales; ix) los hechos atribuibles a grupos armados no identificados, y x) por grupos de seguridad privados."

[8] Consejo de Estado. Sección Primera. Radicación n. ${ }^{\circ}$ 11001-03-24-000-2009-00129-00. Sentencia de 16 de abril de 2015. C. P. Marco Antonio Velilla Moreno.

[9] Dispone el artículo 10 de la Declaración Universal de los Derechos Humanos “Toda persona tiene derecho, en condiciones de plena igualdad, a ser oída públicamente y con justicia por un tribunal independiente e imparcial, para la determinación de sus derechos y obligaciones o para el examen de cualquier acusación contra ella en materia penal”. Organización de las Naciones Unidas. Declaración Universal de los Derechos Humanos, art. 2, (1948).

[10] Dispone la Corte Constitucional. Sentencia C-771 del 13 de octubre de 2011. Magistrado Ponente: Nilson Pinilla. Se entiende por justicia transicional "una institución jurídica a través de la cual se pretenden hilvanar e integrar ingentes esfuerzos, que aplican las sociedades para enfrentar las consecuencias de violaciones masivas y abusos generalizados o sistemáticos en materia de derechos humanos, sufridos en un conflicto, hacia una etapa constructiva de paz, respeto, reconciliación y consolidación de la democracia situaciones de excepción frente a lo que resultaría de la aplicación de las instituciones penales comunes(...)”.

[11] Corte Constitucional de Colombia. Sentencia C-286 del 20 de mayo de 2014. Magistrado Ponente: Luis Ernesto Vargas Silva.

[12] Ley 1448 de 2011. Por la cual se dictan medidas de atención, asistencia y reparación integral a las víctimas del conflicto armado interno y se dictan otras disposiciones. D.O No. 48096. 10 de junio de 2011. Capítulo II. 
[13] Nelson Camilo León y Rodrigo Uprimny. La restitución de tierras, los imperativos de la justicia transicional y los principios del derecho privado, en Democracia, Justicia y Sociedad. Diez años de investigación en Dejusticia, 723 (Mauricio García Villegas, María Adelaida Ceballos Bedolla eds., 2016).

[14] Dispone el artículo 32 en el parágrafo 1 de la Ley 1448 de 2011.

[15] Instituto de Ciencia Política Hernán Echavarría Olózaga, Análisis de la Ley de Víctimas y Restitución de Tierras - Ley 1448 de 2011: Antecedentes, logros y desafíos desde la óptica del Desarrollo Rural, Nota de política Rural, n. ${ }^{\circ}$ 3, 1-8 (2014).

[16] Jaime Orlando Santofimio Gamboa, Compendio de derecho administrativo, Ed. Universidad Externado de Colombia, 779-780 (1 ${ }^{\text {ra }}$ ed., 2017).

[17] Corte interamericana de derechos humanos. Sentencia del 31 de enero de 2006. Caso la masacre de Pueblo Viejo vs Colombia. En la cual estableció que puede derivarse responsabilidad extracontractual del Estado por actos cometidos por particulares (grupos ilegales) que lesionen derechos consagrados en la Convención Interamericana.

[18] Corte Constitucional de Colombia, Sentencia C-916 del 29 de octubre de 2002. Magistrado Ponente: Manuel José Cepeda Espinosa.

[19] Corte Constitucional de Colombia. Sentencia C 228 del 3 de abril de 2002. Magistrado Ponente: Manuel José Cepeda Espinosa y Eduardo Montealegre Lynett.

[20] Corte Constitucional. Sentencia C 454/2006 del 7 de junio de 2006. Magistrado Ponente: Jaime Córdoba Triviño corregida por el Auto 248 de 2006.

[21] Corte Constitucional. Sentencia T 458 del 15 de junio de 2010. Magistrado Ponente: Luis Ernesto Vargas Silva.

[22] Corte Constitucional. Sentencia C-099 del 27 de febrero de 2013. Magistrado Ponente: María Victoria Calle Correa.

[23] Corte Constitucional de Colombia. Sentencia T 083/2017 del 13 de febrero de 2017. Magistrado Ponente: Alejandro Linares Cantillo.

[24] Como dispone el artículo 25 de la Constitución Política: "Los tratados y convenios internacionales ratificados por el Congreso, que reconocen los derechos humanos y que prohíben su limitación en los estados de excepción, prevalecen en el orden interno. (...)Los derechos y deberes consagrados en esta Carta se interpretarán de conformidad con los tratados internacionales sobre derechos humanos ratificados por Colombia.. Constitución Política de Colombia [Const.]. Art. 25.7 de julio de 1991 (Colombia).

[25] Jaime Orlando Santofimio Gamboa, op. cit., 782.

[26] Como dispone el artículo 25 de la Ley 1448 de 2011. Por la cual se dictan medidas de atención, asistencia y reparación integral a las víctimas del conflicto armado interno y se dictan otras disposiciones. 10 de junio de 2011. D.O. n. 48096 : "Las víctimas tienen derecho a ser reparadas de manera adecuada, diferenciada, transformadora y efectiva por el daño que han sufrido como consecuencia de las violaciones de que trata el artículo $3^{\circ}$ de la presente Ley.La reparación comprende las medidas de restitución, indemnización, rehabilitación, satisfacción y garantías de no repetición, en sus dimensiones individual, colectiva, material, moral y simbólica. Cada una de estas medidas será implementada a favor de la víctima dependiendo de la vulneración en sus derechos y las características del hecho victimizante.Parágrafo $1^{\circ}$. Las medidas de asistencia adicionales consagradas en la presente ley propenden por la reparación integral de las víctimas y se consideran complementarias a las medidas de reparación al aumentar su impacto en la población beneficiaria. Por lo tanto, se reconoce el efecto reparador de las medidas de asistencia establecidas en la presente ley, en la medida en que consagren acciones adicionales a las desarrolladas en el marco de la política social del Gobierno Nacional para la población vulnerable, incluyan criterios de priorización, así como características y elementos particulares que responden a las necesidades específicas de las víctimas.No obstante, este efecto reparador de las medidas de asistencia, estas no sustituyen o reemplazan a las medidas de reparación. Por lo tanto, el costo o las erogaciones en las que incurra el Estado en la prestación de los servicios de asistencia, en ningún caso serán descontados de la indemnización administrativa o judicial a que tienen derecho las víctimas."

[27] Consejo de Estado. Sala de lo Contencioso Administrativo, Sección Tercera, Radicación N. ${ }^{\circ}$ 76001-23-25-000-1996-04058-01(16996). Sentencia del 20 de febrero de 2008. Consejero Ponente: Enrique Gil Botero.

[28] Consejo de Estado. Sección Tercera, Subsección B. Sentencia 19939 del 27 de septiembre de 2013, Consejero Ponente: Stella Conto Díaz del Castillo. 
[29] véase Corte Interamericana de Derechos Humanos. Sentencia de 5 de julio de 2004, serie C, No. 109. Caso de la masacre de 19 comerciantes vs. Colombia; Sentencia de 15 de septiembre de 2005, serie C, No. 134. Caso de la masacre de Mapiripa\#n vs. Colombia; Sentencia de 31 de enero de 2006, serie C, No. 140. Caso de la masacre de Pueblo Bello vs. Colombia; Sentencia de 1 de julio de 2006, serie C, No. 149. Caso de las masacres de Ituango vs. Colombia; Sentencia de 11 de mayo de 2007, serie C, No. 163. Caso de la masacre de La Rochela vs. Colombia.

[30] Rodrigo Uprimny y María Paula Saffon, Reparaciones transformadoras, justicia distributiva y profundización democrática, en Reparar en Colombia: los dilemas en contextos de conflicto, pobreza y exclusión 40-41 (Catalina Díaz Gómez, Nelson Camilo Sánchez, Rodrigo Uprimny Yepes eds., 2009).

[31] Registro único de víctimas. https://www.unidadvictimas.gov.co/es/registro-unico-de-victimas-ruv/37394 recuperado el 27 de diciembre 2017

[32] Dispone en artículo 90 de la Constitución Política "El Estado responderá patrimonialmente por los daños antijurídicos que le sean imputables, causados por la acción o la omisión de las autoridades”. Constitución Política de Colombia [Const]. Art. 90. 7 de julio de 1991 (Colombia)

[33] Miguel Emilio La Rota, Sebastián Lalinde Ordoñez, Sandra Santa Mora y Rodrigo Uprimny Yepes, Necesidades Juri\#dicas y acceso a la Justicia en Colombia, Ed. Dejusticia, 215 (2014)

[34] Christine Bréchon-Moulénes, Les Régimes Législatifs de Responsabilité Publique, 112 Bibliothèque de droit public, 9 (1974). (traducción libre)

[35] Aura Patricia Bolívar Jaime, Mecanismos de reparación en perspectiva comparada, en Reparar en Colombia: los dilemas en contextos de conflicto, pobreza y exclusión 74 (Catalina Díaz Gómez, Nelson Camilo Sánchez, Rodrigo Uprimny Yepes eds., 2009).

[36] Corte Constitucional de Colombia. Sentencia T 370/2013 del 27 de junio de 2013. Magistrado Ponente: Jorge Iván Palacio.

[37] Corte Constitucional de Colombia. Sentencia T 908/2014 del 26 de noviembre 2014. Magistrado Ponente: Mauricio González Cuervo.

[38] Corte Constitucional de Colombia Sentencia C 006/2017 del 18 de enero de 2017. Magistrado Ponente: María Victoria Calle Correa.

[39] Consejo de Estado. Sección 2, Subsección B. Sentencia de 10 de noviembre de 2014. Consejero Ponente: Gerardo Arenas Monsalve.

[40] Corte Constitucional. Sentencia C-529 del 23 de junio de 2010. Magistrado Ponente: Mauricio González Cuervo

[41] Véase, Consejo de Estado. Sección Tercera, Subsección C. Sentencia 28417 de 22 de enero de 2014, Consejero Ponente: Enrique Gil Botero. "En primera medida, la Ley establece una condición restrictiva para reconocer el daño y es la fecha de la ocurrencia de los hechos, por lo que las personas que hayan sufrido un daño posterior al 1 de enero de 1985 serán consideradas víctimas, sin embargo sus hechos deben ser denunciados dentro de los siguientes dos o cuatro años contados a partir de la publicación de la Ley; aclarando lo anterior, se establece un régimen de prescripción del derecho al reconocimiento como víctima derivado de esta norma.."

[42] Consejo de Estado. Sala de lo Contencioso Administrativo, Sección Tercera. Radicación n. ${ }^{\circ}$ 25000-23-26-000-1996-02964(19807). Sentencia del 16 de marzo de 2012. Consejero Ponente: Stella Conto Díaz Del Castillo.

[43] Corte Constitucional. Sentencia SU-254 del 24 de abril de 2013. Magistrado Ponente: Luis Ernesto Vargas Silva.

[44] Corte Constitucional de Colombia. Sentencia C-286 del 20 de mayo de 2014. Magistrado Ponente: Luis Ernesto Vargas Silva.

[45] Consejo De Estado. Sala de lo Contencioso Administrativo, Sección Tercera. Radicación n. ${ }^{\circ}$ 07001-23-31-000-2000-00182-01. Sentencia del 18 De julio de 2012. Consejero Ponente: Olga Mélida Valle De La Hoz.

[46] Consejo de Estado. Sala de lo Contencioso Administrativo, Sección Tercera. Radicación n. ${ }^{\circ}$ 19001-23-31-000-1999-00984-01. Sentencia 24108 del 1 de Julio de 2015. Consejera Ponente: Olga Mélida Valle De La Hoz. 
Margarita Cárdenas Poveda. Criterios para reparar a las víctimas del conflicto armado...

[47] Consejo de Estado. Radicación n. ${ }^{\circ}$ 19001-23-31-000-1999-01166-01. Sentencia 22732. Consejero Ponente: Mauricio Fajardo Gómez.

[48] Defensoría del Pueblo y GIZ (Deutsche Gesellschaft fur Internationale Zusammenarbeit), Contenido y Alcance del Derecho a la Reparación. Instrumentos para la protección y observancia de las víctimas. http://www.defensoria.gov.co/public/ pdf/04/alcanceReparacion.pdf

[49] Andrés Casas-Casas y Germán Herrera-Toloza, El juego político de las reparaciones: un marco analítico de las reparaciones en procesos de justicia transicional, 13 Papel Político. n. ${ }^{\circ}$ 1, $197-223$ (2013).

[50] Corte Constitucional de Colombia. Sentencia C 370/06 del 18 de mayo de 2006. Magistrado Ponente: Manuel José Cepeda Espinosa y otros.

\section{Licencia Creative Commons CC BY 4.0}

Para citar este artículo/To cite this article: Margarita Cárdenas Poveda, Criterios para reparar a las víctimas del conflicto armado desde la perspectiva de la administración pública y del juez administrativo colombiano, 68 Vniversitas, n. ${ }^{\circ} 139$ (2019). https://doi.org/10.11144/Javeriana.vj139.cprv 